\title{
Airborne Dust Cloud Measurements at the INL National Security Test Range
}

Michael L. Abbott Norm Stanley

Larry Radke Charles Smeltzer

September 2007

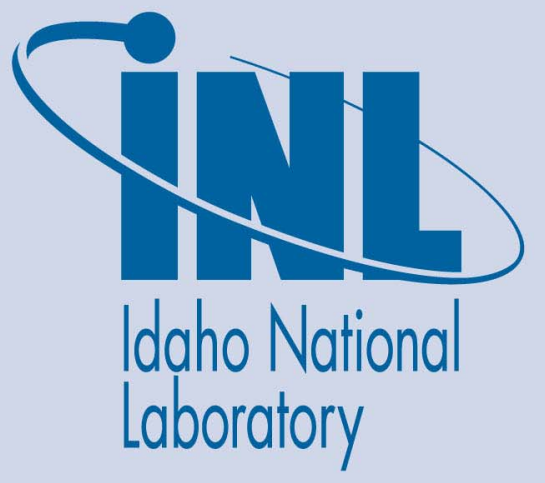

The INL is a U.S. Department of Energy National Laboratory operated by Battelle Energy Alliance 
INL/EXT-07-13173

\section{Airborne Dust Cloud Measurements at the INL National Security Test Range}

${ }^{1}$ Idaho National Laboratory

Michael L. Abbott ${ }^{1}$

Norm Stanley ${ }^{1}$

Larry Radke ${ }^{2}$

Charles Smeltzer ${ }^{2}$

${ }^{2}$ Atmospheric Research Consultants LLC

September 2007

\section{Idaho National Laboratory \\ Idaho Falls, Idaho 83415 \\ and}

Atmospheric Research Consultants LLC

Saunderstown, Rhode Island 02873

Prepared for the

U.S. Department of Energy

Office of Nuclear Energy

Under DOE Idaho Operations Office

Contract DE-AC07-05ID14517 


\title{
Airborne Dust Cloud Measurements at the INL National Security Test Range
}

\author{
INL/EXT-07-13173
}

September 2007

Approved by: 



\begin{abstract}
On July 11, 2007, a surface, high-explosive test ( $<20,000 \mathrm{lb}$ TNT-equivalent) was carried out at the National Security Test Range (NSTR) on the Idaho National Laboratory (INL) Site. Aircraft-mounted rapid response (1-sec) particulate monitors were used to measure airborne PM-10 concentrations directly in the dust cloud and to develop a PM-10 emission factor that could be used for subsequent tests at the NSTR. The blast produced a mushroom-like dust cloud that rose approximately 2,500-3,000 ft above ground level, which quickly dissipated (within 5 miles of the source). In general, the cloud was smaller and less persistent than expected, or that might occur in other areas, likely due to the coarse sand and subsurface conditions that characterize the immediate NSTR area. Maximum short time-averaged (1-sec) PM-10 concentrations at the center of the cloud immediately after the event reached $421 \mu \mathrm{g} \mathrm{m}^{-3}$ but were reduced (by atmospheric dispersion and fallout) to near background levels $\left(\sim 10 \mu \mathrm{g} \mathrm{m}^{-3}\right)$ after about 15 minutes. This occurred well within the INL Site boundary, about $8 \mathrm{~km}$ (5 miles) from the NSTR source.

These findings demonstrate that maximum concentrations in ambient air beyond the INL Site boundary (closest is $11.2 \mathrm{~km}$ from NSTR) from these types of tests would be well within the $150 \mu \mathrm{g} \mathrm{m}^{-3}$ 24-hour National Ambient Air Quality Standard for PM-10. Aircraft measurements and geostatistical techniques were used to successfully quantify the initial volume $\left(1.64 \mathrm{E}+9 \mathrm{~m}^{3}\right.$ or $\left.1.64 \mathrm{~km}^{3}\right)$ and mass $(250 \mathrm{~kg})$ of the PM-10 dust cloud, and a PM-10 emission factor $(20 \mathrm{~kg}$ $\mathrm{m}^{-3}$ crater soil volume) for this specific type of event at NSTR. The $250 \mathrm{~kg}$ of PM-10 mass estimated from this experiment is almost seven-times higher than the $36 \mathrm{~kg}$ estimated for the environmental assessment (DOE-ID 2007) using available Environmental Protection Agency (EPA 1995) emission factors. This experiment demonstrated that advanced aircraft-mounted instruments operated by experienced atmospheric research groups, such as the INL and Airborne Research Consultants LLC , can safely and effectively assess difficult air pollutant questions at the INL Site and elsewhere that cannot be otherwise answered. This site-specific, measurement-based assessment provides valuable input to stakeholders and NSTR project staff in judging the risks associated with these types of events and the development of future experimental design and environmental impact assessments.
\end{abstract}




\section{CONTENTS}

ACRONYMS

ix

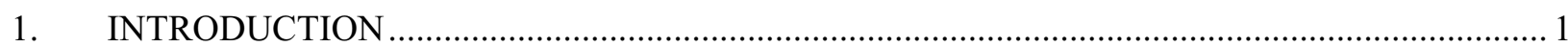

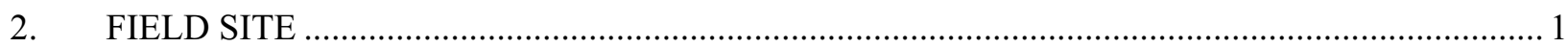

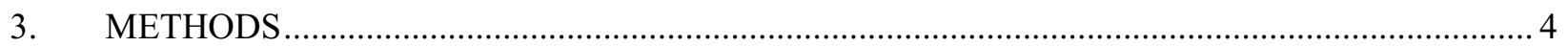

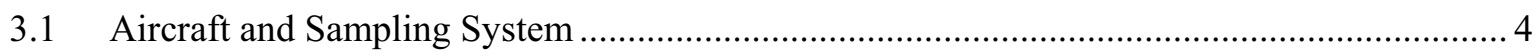

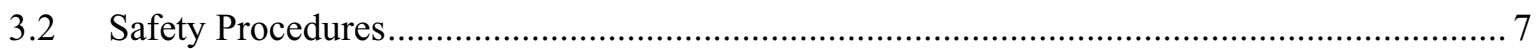

3.3 Sampling Plan and Data Analysis ............................................................................ 8

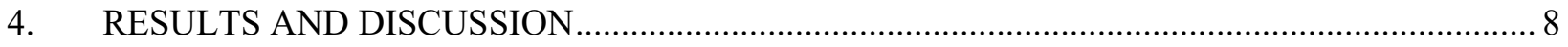

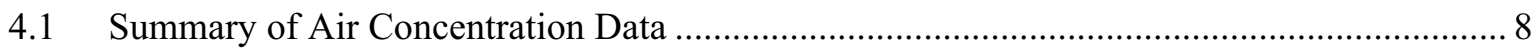

4.2 Estimation of Initial Cloud Volume and PM-10 Mass....................................................... 11

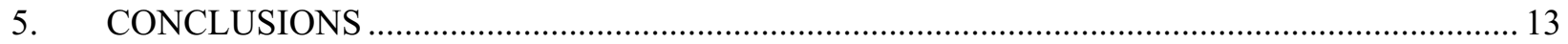

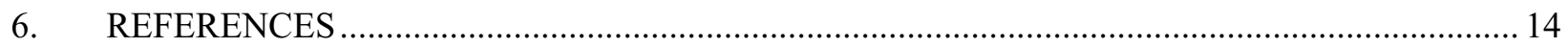

\section{FIGURES}

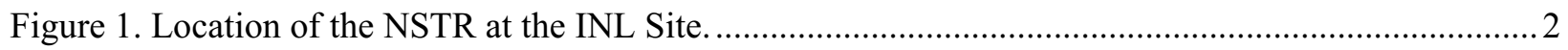

Figure 2. Wind speed and direction during the time of the event (7/11/07 1135-1200 MDT

[Mountain Daylight Time]) from the National Oceanic and Atmospheric

Administration sounder located approximately 12 miles west of the NSTR at the INL

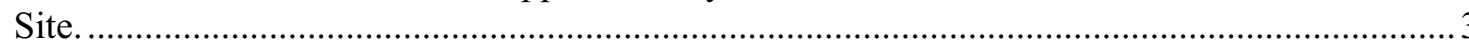

Figure 3. Schematic of the vortex ring and mushroom cloud generated by large surface explosions.

Figure 4. ARC Cessna 337 Skymaster, "Mercury Too" and crew, left to right, Mr. Alex Dunn, pilot, Mr. Charles Smeltzer, meteorologist/scientist, and Dr. Lawrence Radke, Chief Scientist, ARC.

Figure 5. Interior cabin of the Skymaster showing the data logger (left), DataRam 4 PM-10 sampler (center), and split sampling line to vacuum booster pump and DataRam 4 (see subsequent description).

Figure 6. Thermo Scientific DataRam 4 2-wavelength light-scattering nephelometer...............................6

Figure 7. Radiance Research integrating nephelometer....................................................................... 7

Figure 8. Isokinetic sample line inlet installed on the ARC Skymaster (for the DataRam 4). ................... 7

Figure 9. View of the dust cloud from the ARC aircraft (5 miles distant at 3,000 ft AGL)....................9

Figure 10. View of the dust cloud from the ground, 1-mile away from ground zero............................. 9

Figure 11. Aircraft sampling flight path through cloud from 1134 MDT to 1200 MDT......................... 10 
Figure 12. 1-sec PM-10 concentrations (in $\mu \mathrm{g} \mathrm{m}^{-3}$ ) and particle median mass diameter ( $\mathrm{mmd}$, in $\mu \mathrm{m})$ during the period when the dust plume was visible (1734-1801 UTC [Coordinated Universal Time]; 1134-1201 MDT)

Figure 13. Interpolated PM-10 concentration isopleths from the first three sampling passes.....

Figure 14. Surfer $8 \circledR$ "volume" surface used to integrate lateral cloud concentrations (giving mass per unit cloud height in $\mu \mathrm{g} \mathrm{m}^{-1}$ ). 


\section{ACRONYMS}

AGL above ground level

ARC Airborne Research Consultants LLC

DOE Department of Energy

EA environmental assessment

EPA Environmental Protection Agency

FAA Federal Aviation Administration

INL Idaho National Laboratory

MDT Mountain Daylight Time

NSTR National Security Test Range

PI principal investigator

PM-10 particulate matter less than $10 \mu \mathrm{m}$ in diameter

TFR temporary flight restriction

TNT trinitrotoluene

UTC Coordinated Universal Time 


\section{Airborne Dust Cloud Measurements at the INL National Security Test Range}

\section{INTRODUCTION}

The Idaho National Laboratory (INL) established a National Security Test Range (NSTR) during 2007 to analyze the effects of explosives and explosive devices on security systems, facilities, vehicles, structures, and other materials. NSTR is remotely located at the INL Site to protect employees and the public from blast effects, noise, and airborne pollutants. Explosive tests may use up to 20,000 lb of TNT (trinitrotoluene)-equivalent or similar amounts of other conventional explosives. The NSTR environmental assessment (EA) addressed air quality impacts from proposed operations and projected that no ambient air quality standards or permit-to-construct thresholds would be exceeded (DOE 2007). The EA estimated pollutant emissions from the explosive tests based on predicted detonation products or published Environmental Protection Agency (EPA) factors. However, no published particulate matter less than $10 \mu \mathrm{m}$ diameter (PM-10) emission factors could be located for estimating soil suspension from cratering explosive events. The EA assumed a soil PM-10 emission factor of $1.4 \mathrm{lb}$ of PM-10 per ton of explosive based on estimated crater size, the clay fraction of the NSTR soil (3.7\%) and the dry material resuspension fraction of $0.53 \mathrm{lb} \mathrm{ton}^{-1}$ for brick grinding and screening operations (EPA 1995). The approach predicted that up to $80 \mathrm{lb}(36 \mathrm{~kg})$ of PM-10 could be released by a single NSTR event, which would not exceed the National Ambient Air Quality Standard of $150 \mu \mathrm{g} \mathrm{m} \mathrm{m}^{-3}$ at Highway 33 - the nearest public access point located $11.2 \mathrm{~km}$ from the NSTR.

In order to verify the accuracy of the EA's estimated PM-10 emissions and to improve our understanding of soil particulate emissions during future NSTR events, measurements were taken with aircraft-mounted instruments following the first large event on July 11, 2007. The objectives for the NSTR test were to (1) determine maximum PM-10 concentrations as a function of distance from the NSTR detonation site, (2) assess the maximum PM-10 mass suspended, and (3) determine a PM-10 mass/crater soil volume $\left(\mathrm{kg} \mathrm{m}^{-3}\right)$ emission factor.

Since the amount of PM-10 suspended is strongly dependent on the size of the explosion and several soil properties (such as fine particle size fraction, depth to bedrock, soil moisture content), these results apply only to similar charge sizes (e.g., less than 20,000 lbs TNT-equivalent) at the NSTR site under similar climatic (dry mid-summer) conditions. Because PM-10 mass suspended is increased by dryer soil conditions, detonations less than 20,000 lbs during other seasons, such as wetter spring conditions, will likely produce less suspended PM-10 mass. However, these results should not be extrapolated to larger charge sizes or to other testing locations on the INL Site.

\section{FIELD SITE}

The NSTR is located in the remote central portion of the INL Site, an 890 square mile Department of Energy (DOE) facility located in southeastern Idaho about 40 miles west of Idaho Falls (Figure 1). The range lies about 7.1 miles north of the Materials and Fuels Complex and 10 miles south of Test Area North facility. The location is 10.9 miles inside the closest INL Site boundary, 7 miles from the closest public road (Idaho State Highway 33 in the northern half of the INL Site), 13 miles from the closest publicly inhabited building and 1.5 miles west of the Twin Buttes Grazing Allotment, where Bureau of Land Management issues grazing permits. The location was selected because of its remote location on the INL Site, which provides adequate separation from any surrounding population or facilities that could be affected by blast or sound. Additional details on the range can be found in the NSTR environmental assessment (DOE 2007). 
The area around NSTR is relatively flat with barren shallow sandy soils and sparse desert grasses (all shrubs were removed for wildfire control). Surface soil measurements on the day of the test (July 11, $2007)$ indicated a medium-coarse sand $(\sim 95 \%)$ with a bulk density of $1.75 \mathrm{~g} \mathrm{~cm}^{-3}$, porosity of $34 \%$, and soil water-filled pore space of $6 \%$. Less than $5 \%$ of the soil particles were fine sized $(<0.25 \mathrm{~mm})$, indicating a relatively small quantity of potentially suspendable PM-10.

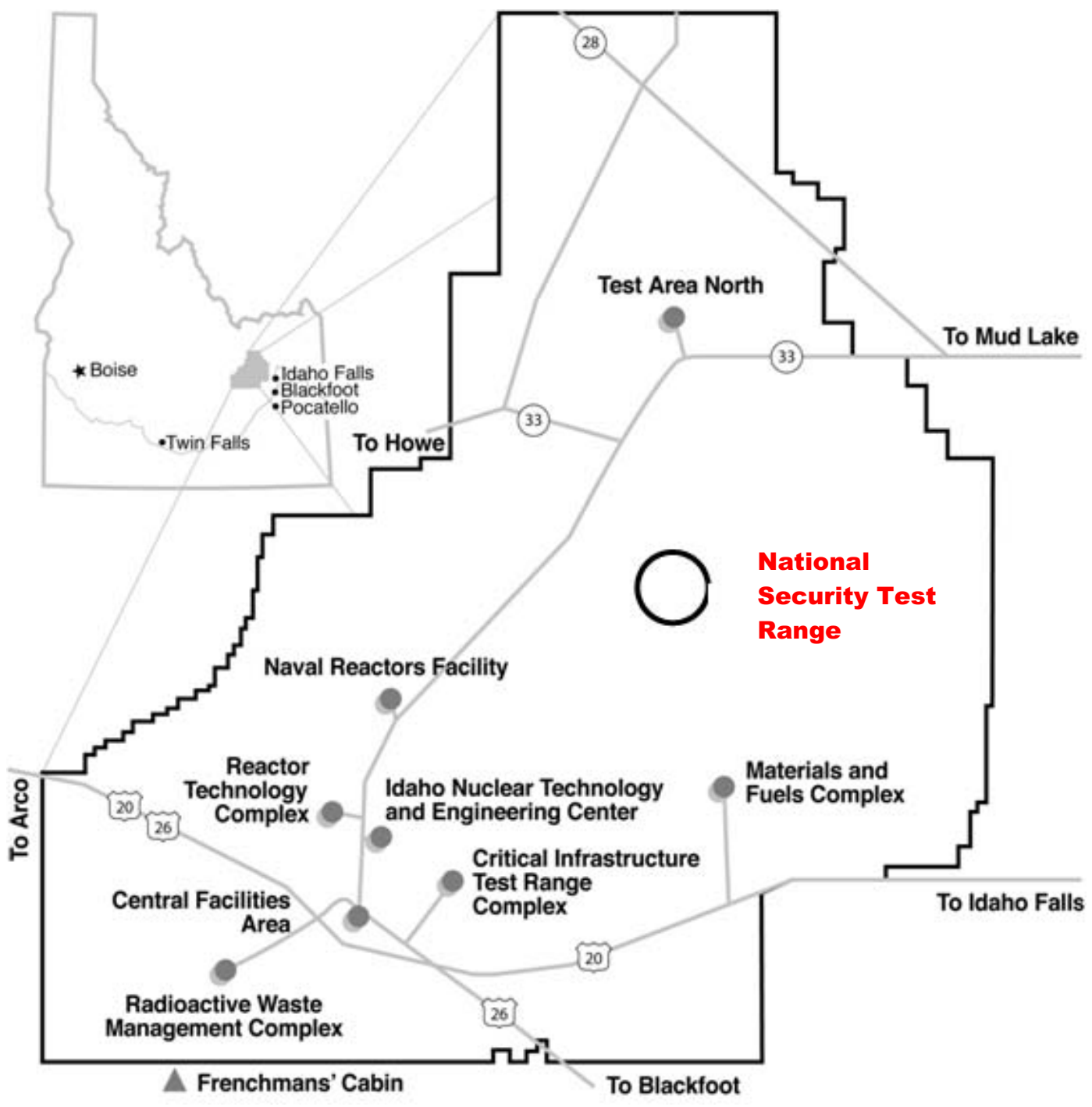

Figure 1. Location of the NSTR at the INL Site.

The surface weather on the day of the test was clear with high cirrus clouds and modest (10-15 mph) winds from the northeast (Figure 2). At 2,000-3,000 ft above ground level (AGL), the winds speed increased to $25 \mathrm{mph}$ and shifted from northeast to east. This wind shift continued at higher altitudes rotating clockwise to 270 degrees (from the west) at 5,000 ft AGL. Above this, the winds shifted rapidly counterclockwise back to 025 degrees (from the northeast) at 5,500 ft AGL and then clockwise to 330 degrees (from the northwest) above 6,000 ft AGL. 

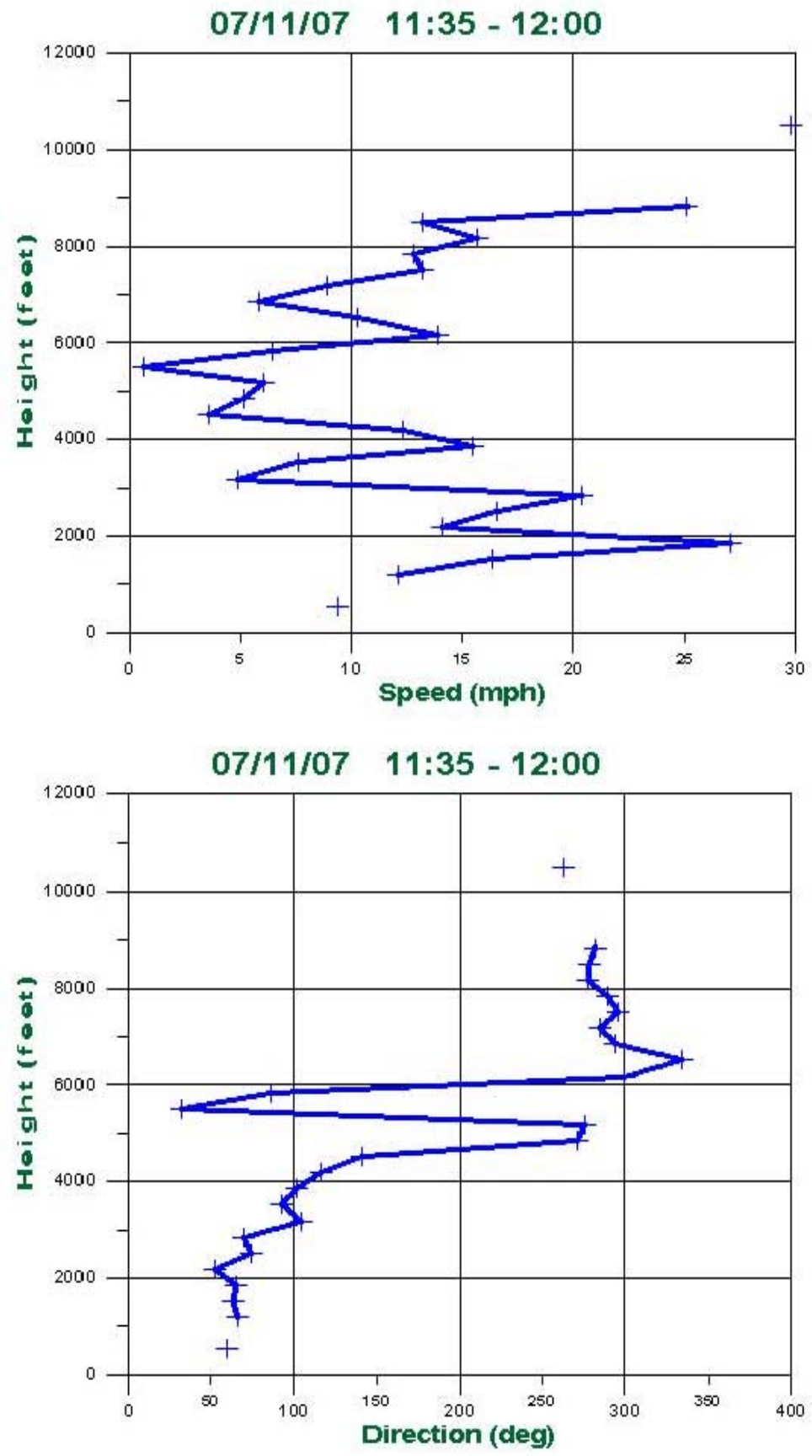

Figure 2. Wind speed and direction during the time of the event (7/11/07 1135-1200 MDT [Mountain Daylight Time]) from the National Oceanic and Atmospheric Administration sounder located approximately 12 miles west of the NSTR at the INL Site. 


\section{METHODS}

Explosions of over a few thousand $\mathrm{kg}$ of high explosives produce a supersonically expanding sphere of very hot gases that produces a characteristic ascending vortex ring that rises to form the familiar mushroom cloud (Figure 3). The chimney-like stem acts as an efficient conduit to channel debris from the surface. The hot vortex and its burden of debris rise convectively until expansion and mixing with cooler surrounding air bring the ensemble to thermal equilibrium. Particles larger than $\sim 10 \mu \mathrm{m}$ have significant gravitational fall speeds and "fallout" rather quickly. The smaller particles tend to remain suspended, disperse downwind, and be slowly removed, primarily by cloud processes (Radke et al. 1980; Radke et al. 1984).

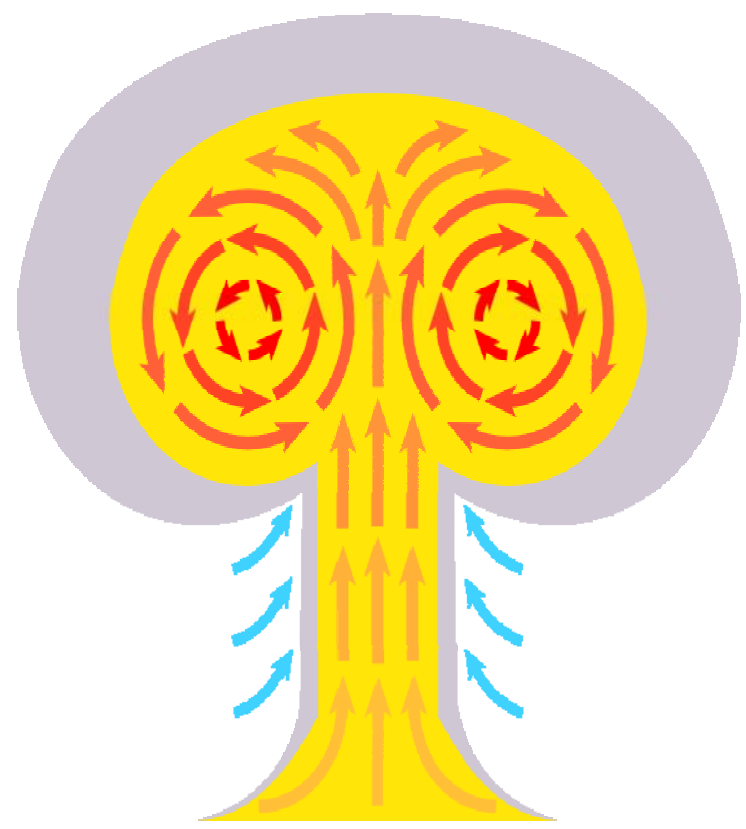

Figure 3. Schematic of the vortex ring and mushroom cloud generated by large surface explosions.

Because of the lofting that occurs in the mushroom cloud, it was decided to make the measurements at altitude directly through the cloud using an aircraft instrumented with two fast-response PM-10 samplers. A subcontractor (Airborne Research Consultants LLC [ARC]) was identified who has significant experience making atmospheric pollutant measurements for research purposes. ARC specializes in mating air pollution instrumentation to a variety of airborne platforms and offered advanced scientific and technical skills to properly install these instruments, make the measurements, and assist in data interpretation. For instance, ARC custom fabricated an external isokinetic sampling probe for the PM-10 sampler, which allowed accurate sampling at typical aircraft speeds of 150-200 mph and developed a custom data analysis system that linked 1-second sample measurements with location, time, altitude, and speed determined by the aircraft global positioning system. This system was flight tested prior to the test, and the required Federal Aviation Administration (FAA) approvals for the aircraft modifications were obtained.

\subsection{Aircraft and Sampling System}

For this experiment, ARC used a Cessna turbo-337 Skymaster, a pressurized 6-seat 2-engine (pushpull) aircraft that provided ample space for instrumentation, pilot, ARC Chief Scientist, and an instrument technician (Figures 4 and 5). The Skymaster's large fuel capacity provides a 4-hour loiter time. 


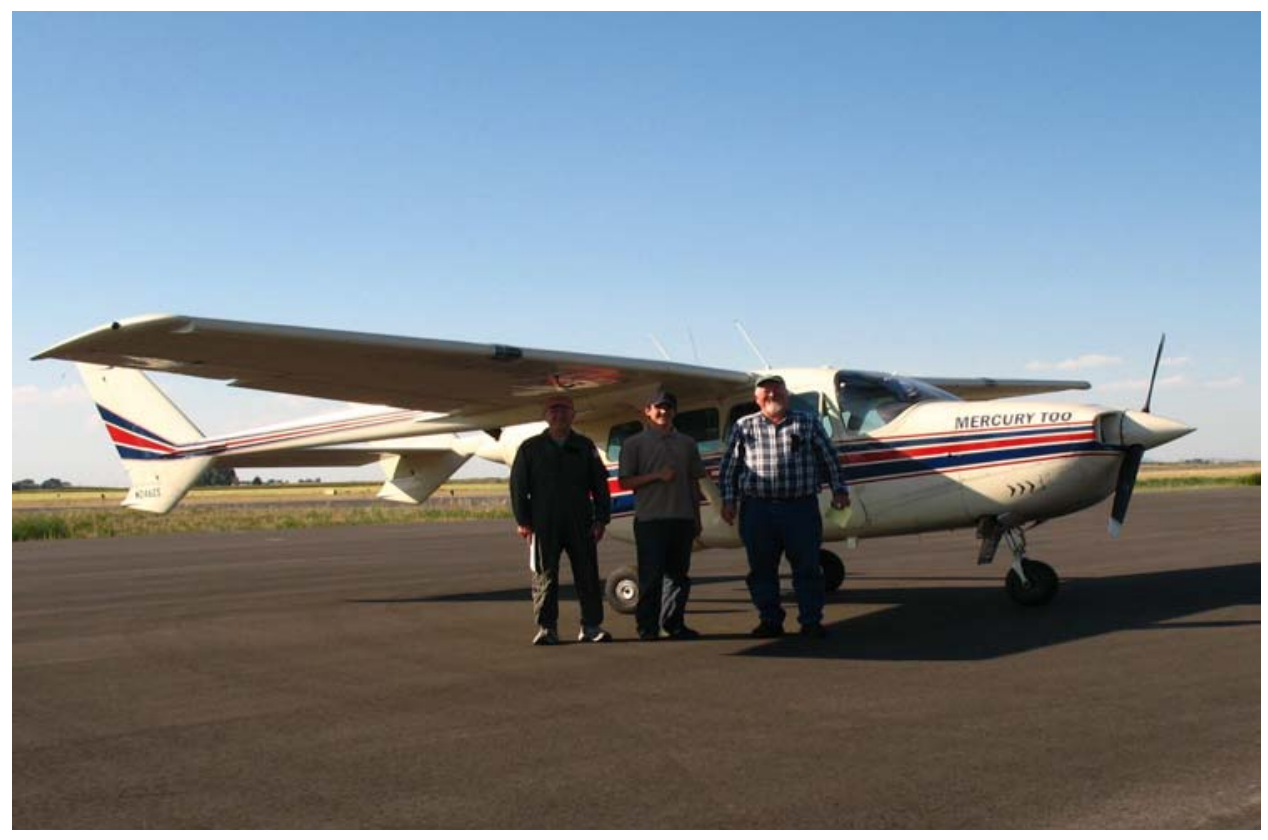

Figure 4. ARC Cessna 337 Skymaster, "Mercury Too" and crew, left to right, Mr. Alex Dunn, pilot, Mr. Charles Smeltzer, meteorologist/scientist, and Dr. Lawrence Radke, Chief Scientist, ARC.

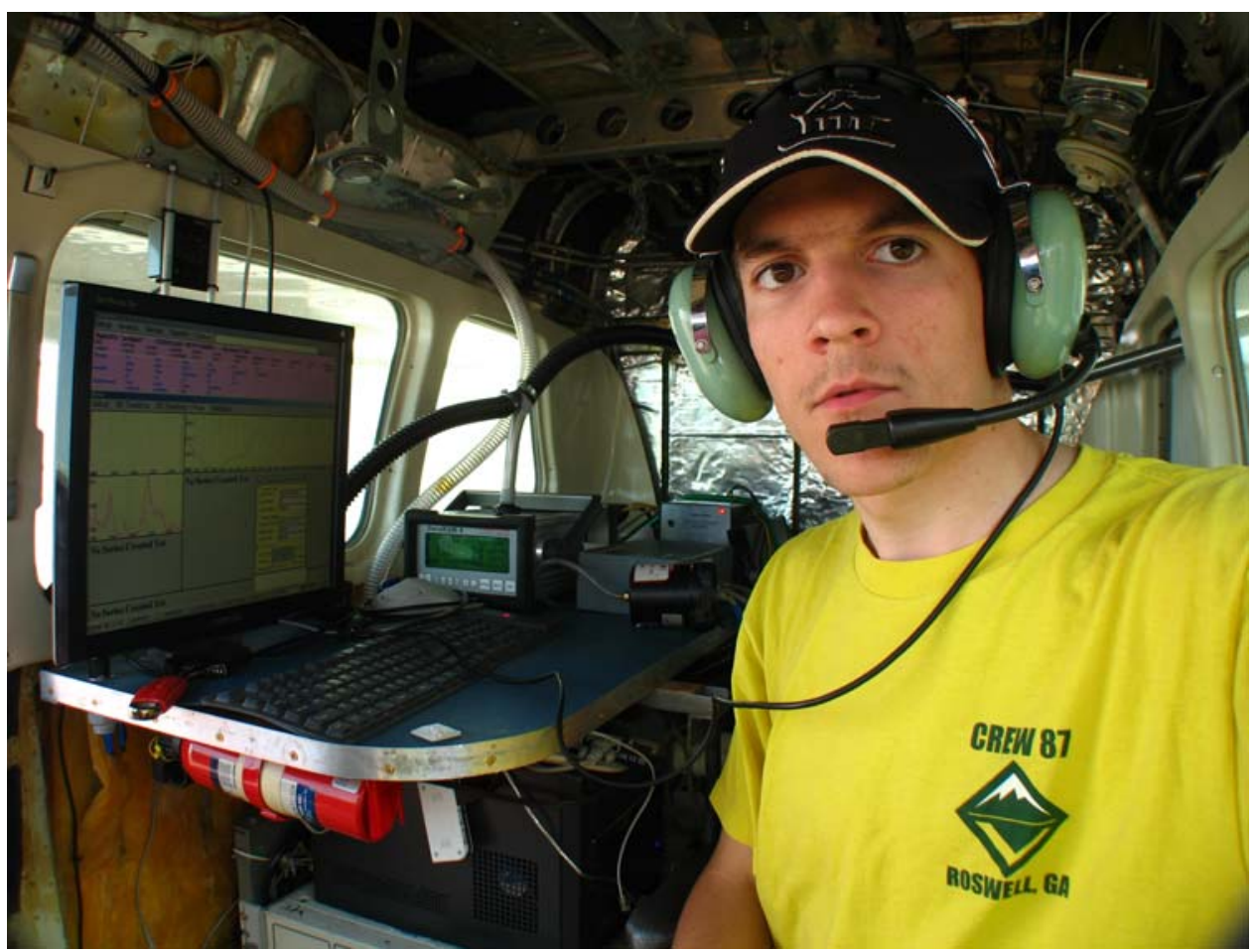

Figure 5. Interior cabin of the Skymaster showing the data logger (left), DataRam 4 PM-10 sampler (center), and split sampling line to vacuum booster pump and DataRam 4 (see subsequent description). 
Two fast-response (1-second) sampling instruments were used to estimate PM-10 concentrations:

- Thermo Scientific ${ }^{\mathrm{a}}$ DataRam $4^{\mathrm{TM}}$ (Figure 6). This instrument is a small two-wavelength light scattering nephelometer that continuously monitors and logs real-time concentrations and median particle size diameter of airborne dust. It was equipped with a PM-10 $(0.08-10 \mu \mathrm{m})$ particle size discriminator with a linear response over a concentration range of $0.001-400 \mathrm{mg} \mathrm{m}^{-3}(1-400,000 \mu \mathrm{g}$ $\left.\mathrm{m}^{-3}\right)$. The 2-sigma precision is $\pm 1 \%$ of reading or $\pm 1 \mu \mathrm{g} \mathrm{m}^{-3}$, whichever is greater. The accuracy, referenced to gravimetric calibration (National Institute of Standards and Technology traceable) with SAE fine test dust ( $\mathrm{mmd}=2-3 \mu \mathrm{m})$, is $\pm 2 \%$ of reading \pm precision. The instrument was factory calibrated by Thermo prior to the test. For this test, the DataRam was set to a measurement frequency of 1 sample per second.

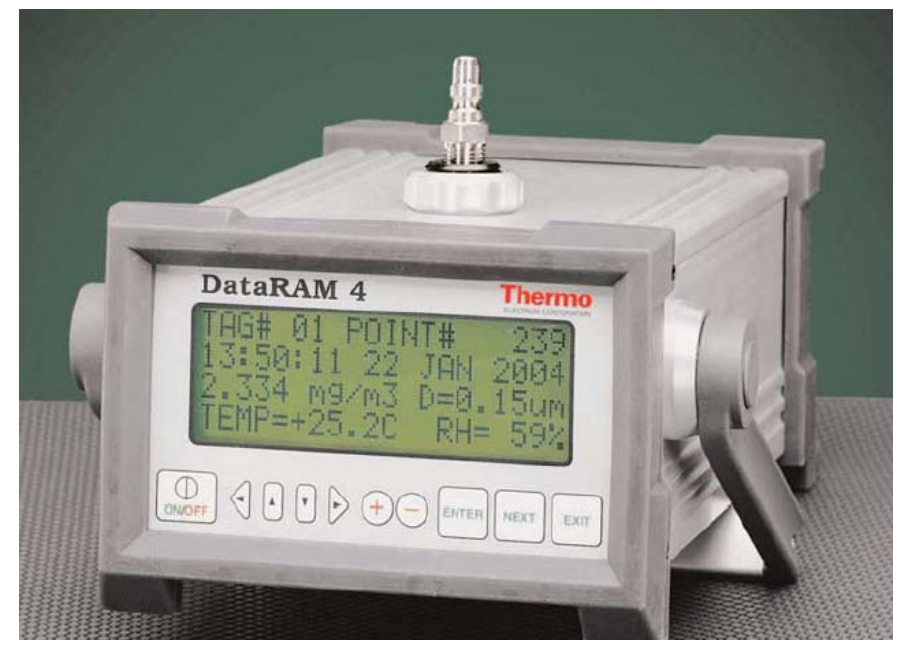

Figure 6. Thermo Scientific DataRam 4 2-wavelength light-scattering nephelometer.

- $\quad$ Radiance Research ${ }^{\mathrm{a}}$ Integrating Nephelometer (Figure 7). This instrument integrates the light scattered by aerosol particles over nearly 180 degrees, which makes it theoretically more sensitive than the DataRam nephelometer. It is most accurate when much of the aerosol particle is in the accumulation mode $(0.1-1 \mu \mathrm{m}$ diameter). For the INL test, the instrument was directly calibrated in units of the light scattering coefficient, $\mathrm{m}^{-1}$. Conversion to mass concentrations requires the use of published analytical conversion factors, which range from $1.7 \mathrm{~m}^{2} \mathrm{~g}^{-1}$ to $5 \mathrm{~m}^{2} \mathrm{~g}^{-1}\left(2 \mathrm{~m}^{2} \mathrm{~g}^{-1}\right.$ mode $)$ (Chow et al. 2002).

For the DataRam sample line, a custom-fabricated isokinetic inlet was developed and installed outside of the aircraft (Figure 8). The inlet has a machined streamlined entrance to keep the aerosolburdened air stream from diverging at the inlet. A supplementary vacuum pump was installed to reduce pressure build-up at the inlet (due to the aircraft airspeed), further reduce particle divergence, and lower the pressure inside the sample line thereby matching the free air stream (aircraft airspeed) velocity. Downstream, the sample diffuses to a larger diameter, slows, and is divided into a mainstream that flows into the vacuum pump and a smaller slower stream that flows into the PM-10 sampler. This sampling system minimizes sampling errors but does not eliminate them. However, most of the sampling losses can likely be attributed to particles greater than $10 \mu \mathrm{m}$.

a. References herein to any specific commercial product, process, or service by trade name, trademark, manufacturer, or otherwise, does not necessarily constitute or imply its endorsement, recommendation, or favoring by the U.S. Government, any agency thereof, or any company affiliated with the INL. 


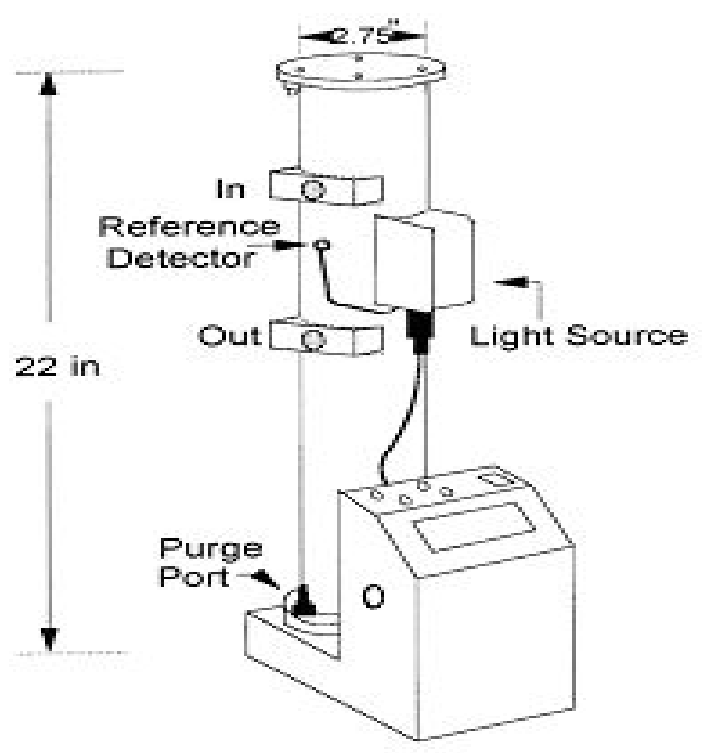

Figure 7. Radiance Research integrating nephelometer.

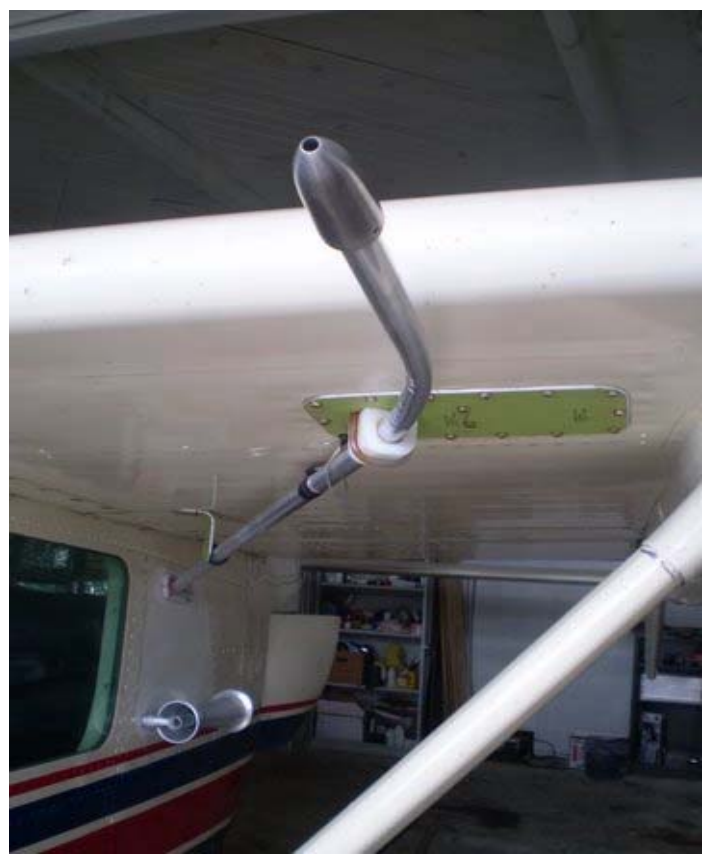

Figure 8. Isokinetic sample line inlet installed on the ARC Skymaster (for the DataRam 4).

\subsection{Safety Procedures}

Numerous aircraft and ground support safety procedures were employed to ensure safe operations. All required INL Site overflight notifications (Warning Communications Center, Operations, Security, Safety, Fire Alarm Center, DOE) were made 2 days prior to the event. The INL principal investigator (PI) confirmed that ARC had valid commercial aviation operational flight procedures for hazardous flight conditions, valid aircraft FAA certifications, and a current pilot license. INL PIs (M. Abbott and N. Stanley) and the Aviation Safety Officer conducted detailed operational and INL aviation safety prebriefings with the ARC aircrew one day prior to the event, which included: scheduling, weather, radio 
protocol, flight paths, altitudes, and flight hazards. A 2-mile radius, 5,000 ft AGL temporary flight restriction (TFR) was established over the NSTR area during the event, and the ARC aircraft remained well outside this area at 3,000 ft AGL until cleared by the Range Safety Officer (after confirmation of a full detonation). Air-ground radio communications were maintained with the aircraft at all times. The aircraft was specially equipped with over-sized engine intake dust filters, and the aircrew wore respirators during their sampling runs until the cloud had dissipated to a low concentration.

\subsection{Sampling Plan and Data Analysis}

The aircraft holding location prior to detonation was established at a point 5 miles from the detonation area and perpendicular to the anticipated trajectory of the mushroom cloud (to the southwest) based on forecasted wind directions. Aircraft holding point altitude (3,000 ft AGL) was set to slightly above the anticipated final dust cloud height after detonation (2,500 ft AGL). After clearance into the TFR (a few minutes after detonation), the aircraft was to make repeated sampling passes through the densest area of the cloud with each pass being approximately 90 degrees from the previous transect. Depending upon cloud dispersion and wind transport direction, additional sampling passes were to be made through the upper and lower one-third of the cloud to assess vertical concentration distribution. Sampling was to be performed until the cloud could no longer be tracked, either visually or by instrument response. Background PM-10 concentrations were obtained from take-off until the first sampling pass through the cloud after detonation (approximately 1 hour). Total cloud PM-10 mass was estimated using the integrating "volume" routine in the mapping software Surfer ${ }^{\circledR} 8$ (Golden Software, Inc., Golden, $\left.\mathrm{CO}^{\mathrm{a}}\right)$.

\section{RESULTS AND DISCUSSION}

\subsection{Summary of Air Concentration Data}

Background PM-10 concentrations prior to the detonation ranged from 5-10 $\mu \mathrm{g} \mathrm{m}^{-3}$, which is consistent with long-term trends at the INL Site and Craters of the Moon National Monument, a Class I air quality area located $40 \mathrm{~km}$ to the west of the INL. The detonation occurred on schedule at approximately 1131 MDT on July 11, 2007 and was clearly visible from the aircraft holding location 5 miles to the east (Figures 9 and 10). The dust cloud rose rapidly to about 2,500 ft AGL and dispersed downwind to the southwest. The aircraft was cleared to begin sampling at 1134 MDT. Numerous sampling transects were flown through the cloud while it was still visible from 1134 MDT to about 1148 MDT (14 minutes) although the aircraft was able to intercept and sample the cloud remnants until about 1200 MDT (Figure 11). Total cloud travel distance from detonation until 1200 MDT (26 minutes) was approximately $10 \mathrm{~km}$, which is well within the INL Site boundary (Figure 11).

The maximum DataRam PM-10 concentration (1-s averaging time) during the first pass through the cloud was $421 \mu \mathrm{g} \mathrm{m}^{-3}$, and the particle median mass diameter (mmd) averaged $0.5 \pm 0.1 \mu \mathrm{m}$ (Figure 12). Maximum cloud concentrations through the subsequent four passes decreased to $112 \mu \mathrm{g} \mathrm{m}^{-3}$. After this time, the cloud was not readily visible anymore, resulting in intermittent elevated $\left(30-100 \mu \mathrm{g} \mathrm{m}^{-3}\right)$ concentrations being detected by the DataRam. 


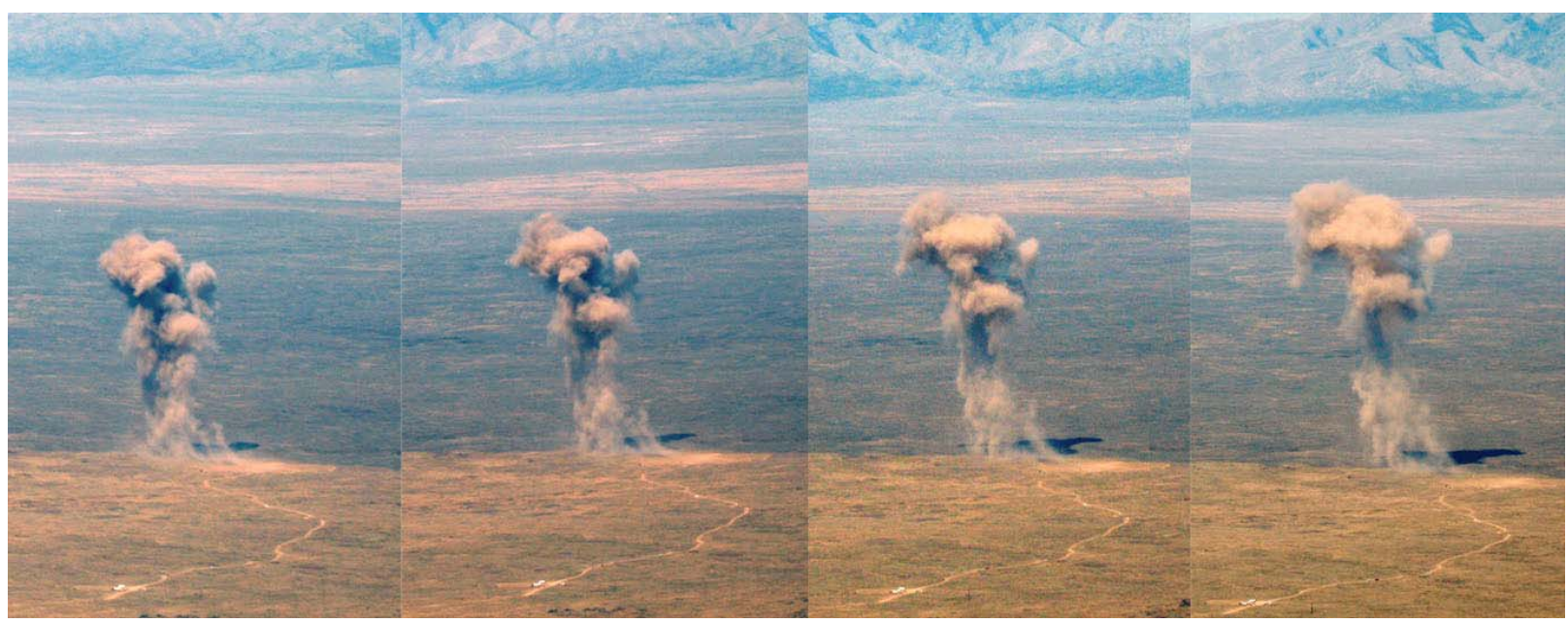

Figure 9. View of the dust cloud from the ARC aircraft (5 miles distant at 3,000 ft AGL).

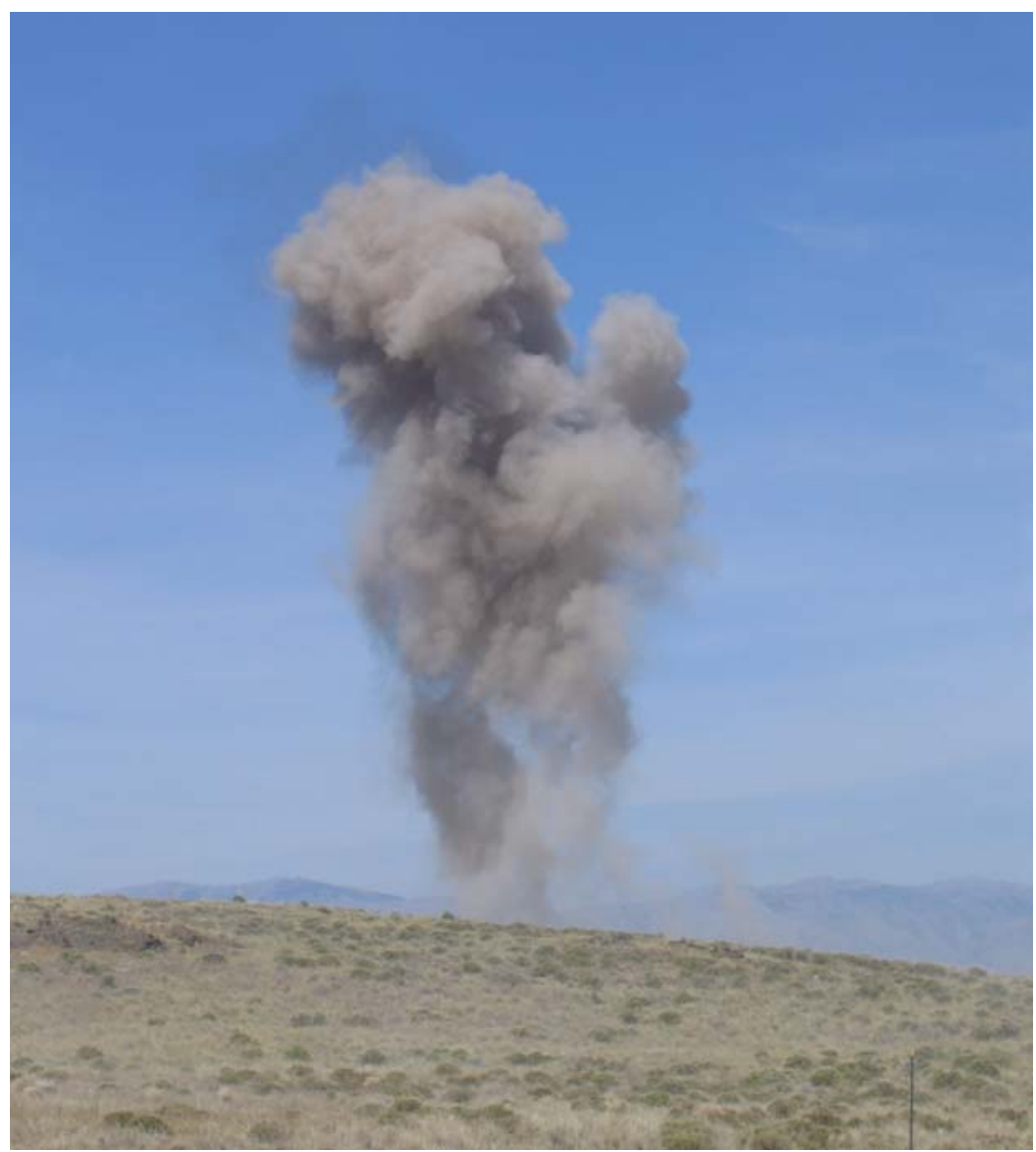

Figure 10. View of the dust cloud from the ground, 1-mile away from ground zero. 


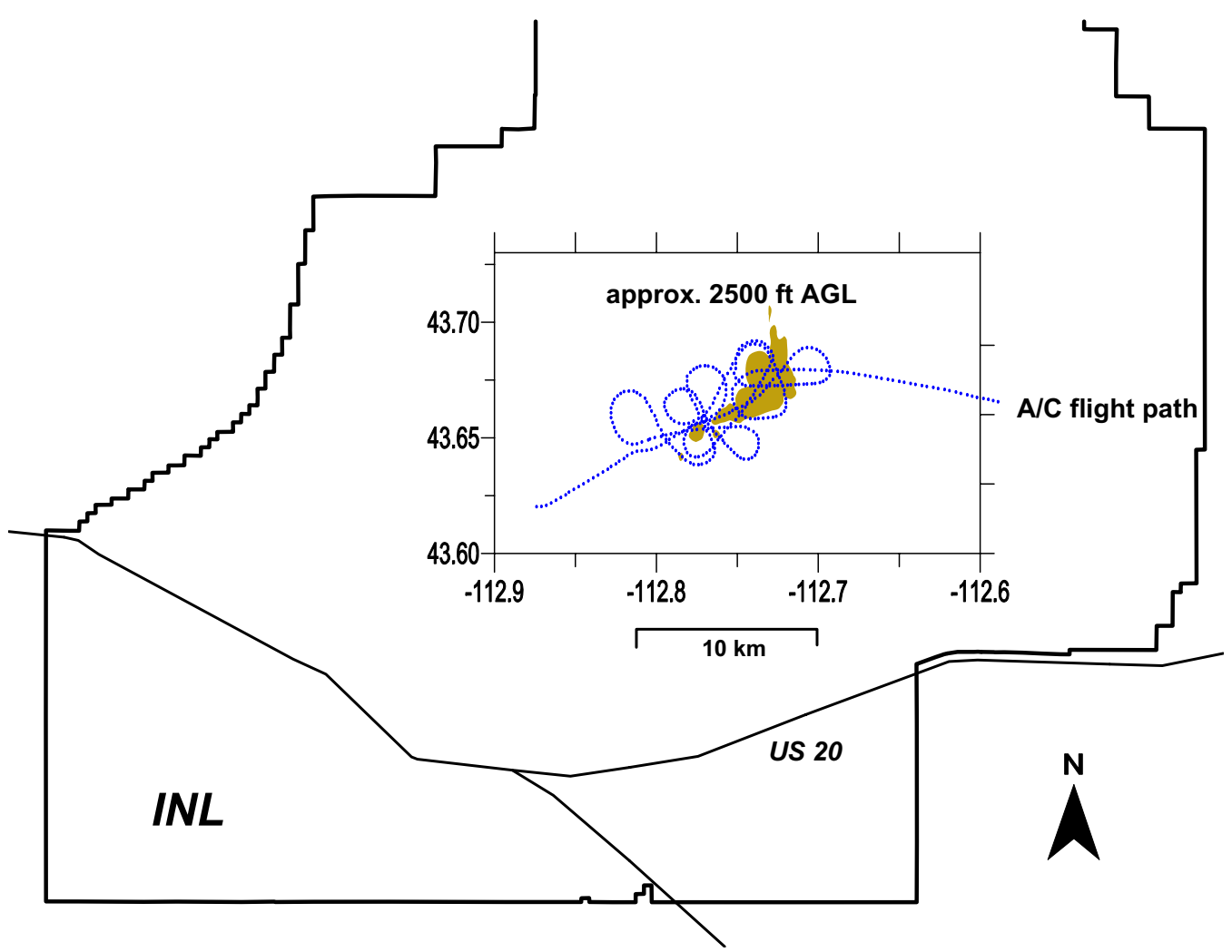

Figure 11. Aircraft sampling flight path through cloud from 1134 MDT to 1200 MDT.

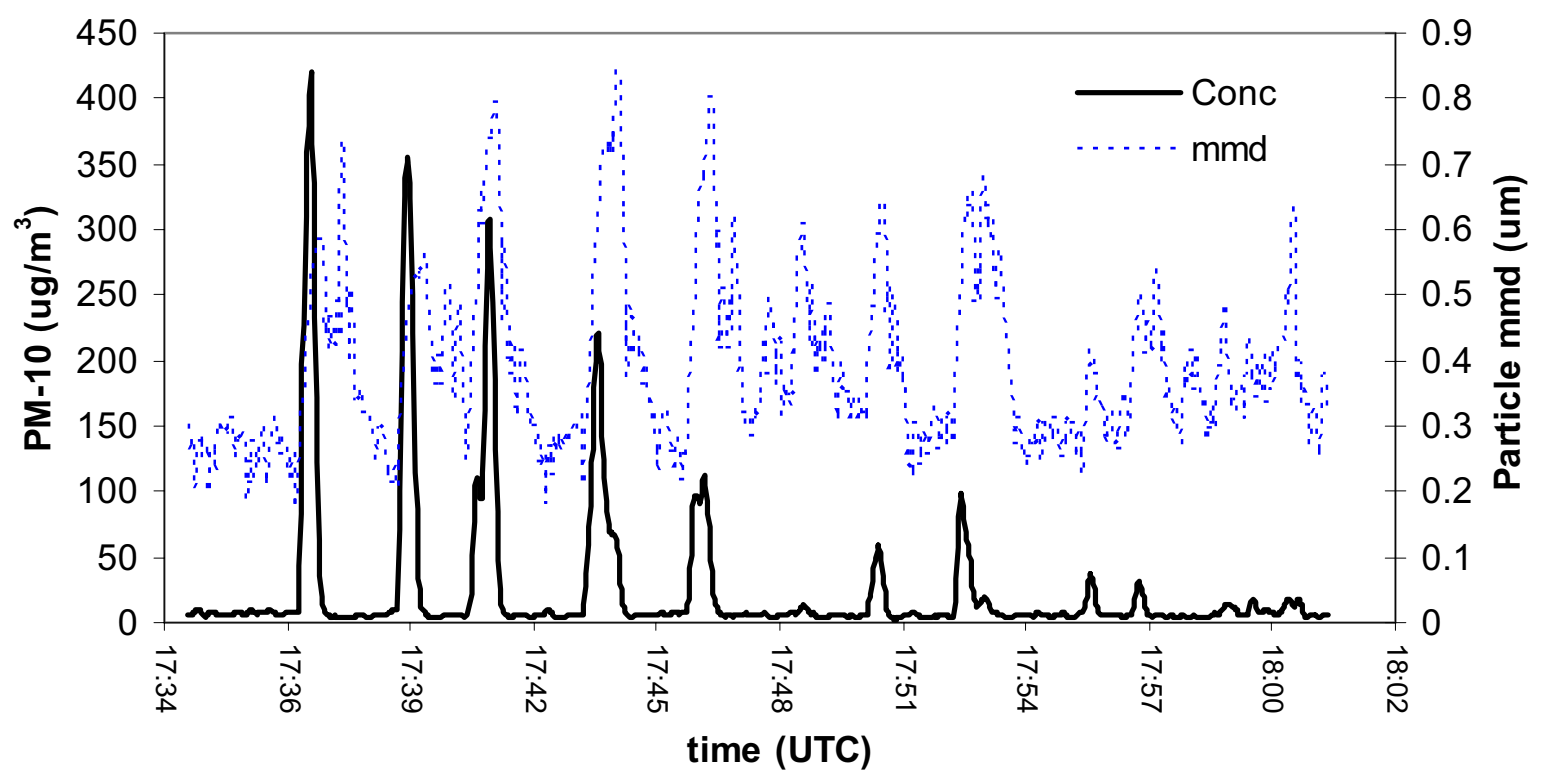

Figure 12. 1-sec PM-10 concentrations (in $\mu \mathrm{g} \mathrm{m}^{-3}$ ) and particle median mass diameter (mmd, in $\left.\mu \mathrm{m}\right)$ during the period when the dust plume was visible (1734-1801 UTC [Coordinated Universal Time]; 1134-1201 MDT). 
Maximum cloud centerline concentrations decreased linearly at approximately $30 \mu \mathrm{g} \mathrm{m}^{-3}$ per minute, which is consistent with puff diffusion rates under the typical daytime atmospheric stability conditions (Hanna et al. 1982). Using this rate, the maximum PM-10 concentration immediately after detonation is estimated to have been approximately $500 \mu \mathrm{g} \mathrm{m}^{-3}$. Extrapolating the observed dispersion rate out to a background value of $10 \mu \mathrm{g} \mathrm{m}^{-3}$ would require 15 minutes, which is about the time the aircraft was able to readily detect the cloud. Under typical daytime wind speed conditions of $20 \mathrm{mph}$ at the INL Site, the dust cloud would travel approximately $8 \mathrm{~km}$ (5 miles) before decreasing in concentration (via dispersion and some fallout) to background levels. This nearest INL Site boundary distance from the NSTR is $10.9 \mathrm{~km}$, indicating that dust clouds of this magnitude will have an inconsequential impact on off-Site ambient air PM-10 concentrations.

\subsection{Estimation of Initial Cloud Volume and PM-10 Mass}

Only the first three sampling passes were evaluated to estimate initial cloud volume and suspended PM-10 mass because these were done in a reasonably short time period $(<5 \mathrm{~min})$ relative to cloud diffusion and downwind transport (i.e., evaluation of subsequent passes would introduce more error because the aircraft was sampling the same cloud mass in a different location). The initial cloud diameter was assumed to be the average distance between the aircraft cloud entry and exit points on the first three passes, which were made through the densest portion of the cloud. The entry/exit points were assumed to be the aircraft global positioning system (GPS) coordinates where the concentration increased/decreased rapidly above/below a background concentration of $10 \mu \mathrm{g} \mathrm{m}^{-3}$. Using these coordinates, initial cloud lateral diameter was estimated to be approximately $2,320 \mathrm{~m}$.

A 2-D contour map of lateral extent of the initial cloud based on the first three passes of sampling data was produced using Surfer $8 \AA$ software (Figure 13). This contour map is based on a gridded array of interpolated concentration values (beyond the aircraft sampling points), which are calculated by Surfer using a kriging routine (a geostatistical gridding method useful for irregulary spaced data).

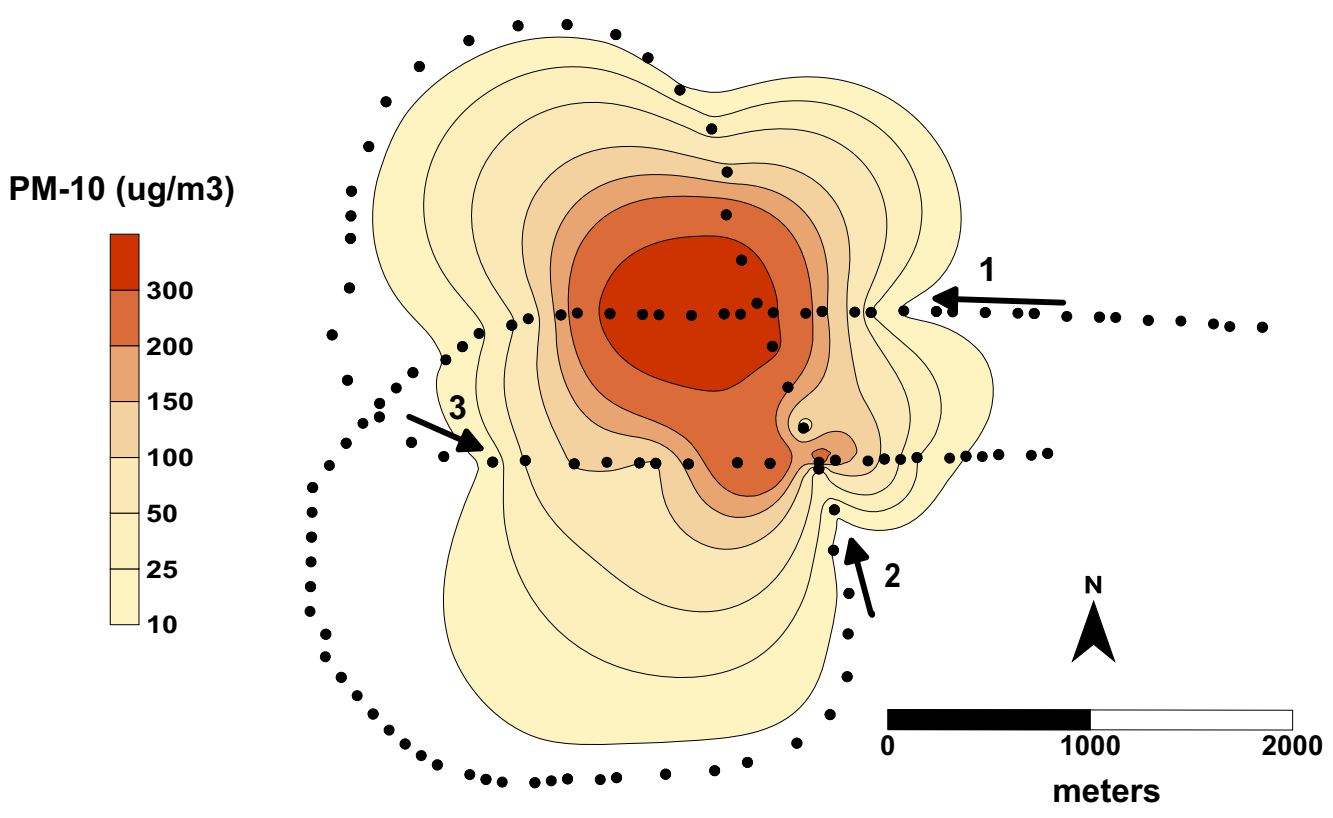

Figure 13. Interpolated PM-10 concentration isopleths from the first three sampling passes. 
Since the cloud dissipated rather quickly, the aircraft was not able to make multiple sampling passes through the upper and lower portions of the cloud to obtain a vertical concentration distribution. The initial thickness or vertical height of the cloud was therefore estimated using the aerial photos (Figure 9) to be approximately $50 \%$ of the lateral diameter $(2,320 \mathrm{~m} \times 0.5=1,160 \mathrm{~m})$.

Further examination of these photos and the Surfer-generated concentration map (Figure 13) indicates the cloud shape could be approximated by an oblate ("squashed") spheroid, the volume of which can be calculated using the formula:

$$
\mathrm{V}=\frac{4}{3} \pi \mathrm{a}^{2} \mathrm{c}
$$

where

$$
\begin{aligned}
& \mathrm{a}=\text { lateral radius (half the lateral diameter }=1,160 \mathrm{~m}) \\
& \mathrm{c}=\operatorname{vertical} \text { radius }(50 \% \text { of lateral radius }=580 \mathrm{~m})
\end{aligned}
$$

Using this method, the initial volume of the PM-10 cloud was estimated to be $1.64 \mathrm{E}+9 \mathrm{~m}^{3}\left(1.64 \mathrm{~km}^{3}\right)$.

Total PM-10 mass suspended (kg) was estimated by:

1. Integrating the Surfer-generated 2-D grid concentrations (Figure 13) over the north-south and westeast axes, giving a mass per unit cloud height of $6.1 \mathrm{E}+8 \mu \mathrm{g} \mathrm{m}^{-1}$ (Figure 14).

2. Calculating the lateral $(\mathrm{X}-\mathrm{Y})$ area of the initial cloud $\left[\pi(1,160 \mathrm{~m})^{2}=4.24 \mathrm{E}+6 \mathrm{~m}^{2}\right]$

3. Calculating an equivalent cylinder height with the above cloud radius $(1,160 \mathrm{~m})$ and a volume equal to that of the oblate spheroid calculated in equation (1). This was done by dividing the oblate spheroid volume $\left(1.64 \mathrm{E}+9 \mathrm{~m}^{3}\right)$ by the area of the initial cloud $\left(4.24 \mathrm{E}+6 \mathrm{~m}^{2}\right)$ giving an equivalent cylinder height of $387 \mathrm{~m}$.

4. Calculating the total cloud PM-10 mass by multiplying the Surfer-integrated areal mass $(6.1 \mathrm{E}+8 \mu \mathrm{g}$ $\mathrm{m}^{-1}$, from [1], above) by the equivalent cylinder height $(387 \mathrm{~m})$. This gives an estimated total PM-10 mass of $2.4 \mathrm{E}+11 \mu \mathrm{g}$ or $240 \mathrm{~kg}$.

Another way to estimate the PM-10 mass suspended is to simply multiply the cloud volume $(1.64 \mathrm{E}+9$ $\left.\mathrm{m}^{3}\right)$ by the average concentration measured through the first three aircraft sample passes $\left(159 \mu \mathrm{g} \mathrm{m}^{-3}\right)$. This gives a total PM-10 mass estimate of $2.6 \mathrm{E}+11 \mu \mathrm{g}$ or $260 \mathrm{~kg}$, slightly higher than the Surfer gridintegration method described above.

The validity of these PM-10 emission estimates (240-260 kg) can be evaluated by comparing them to the estimated fine soil fraction $(<0.25 \mathrm{~mm})$ ejected from the crater. The total crater soil volume was estimated to be $12.74 \mathrm{~m}^{3}$ (J. Weathersby, personal communication). Soil sieve measurements taken prior to the test indicated $\sim 3 \%$ of the surface soil was in the fine fraction $(<0.25 \mathrm{~mm}$ or $250 \mu \mathrm{m})$, giving a total crater fine soil volume of $\sim 0.4 \mathrm{~m}^{3}\left(14 \mathrm{ft}^{3}\right)$. The soil volume equivalent to the estimated PM-10 mass suspended $(240-260 \mathrm{~kg})$ is calculated by dividing the PM-10 mass suspended by the measured surface soil bulk density $\left(1,750 \mathrm{~kg} \mathrm{~m}^{-3}\right)$, giving $\sim 0.14 \mathrm{~m}^{3}\left(5 \mathrm{ft}^{3}\right)$ or about one-third of the total fine $(<250 \mu \mathrm{m})$ soil volume in the crater. Since PM-10 includes only particle sizes less than $10 \mu \mathrm{m}$, this confirms that the PM-10 mass emission estimate is reasonable.

A PM-10 to crater soil volume emission factor $\left(\mathrm{kg} \mathrm{m}^{-3}\right)$ can be calculated by dividing the PM-10 mass estimates by the total crater soil volume $\left(12.74 \mathrm{~m}^{3}\right)$, giving an average emission factor of $20 \mathrm{~kg}$ PM-10 per $\mathrm{m}^{-3}$ total crater soil volume. This emission factor applies only to the NSTR site under the very dry $(6 \%)$ soil moisture levels that were present during the test. 


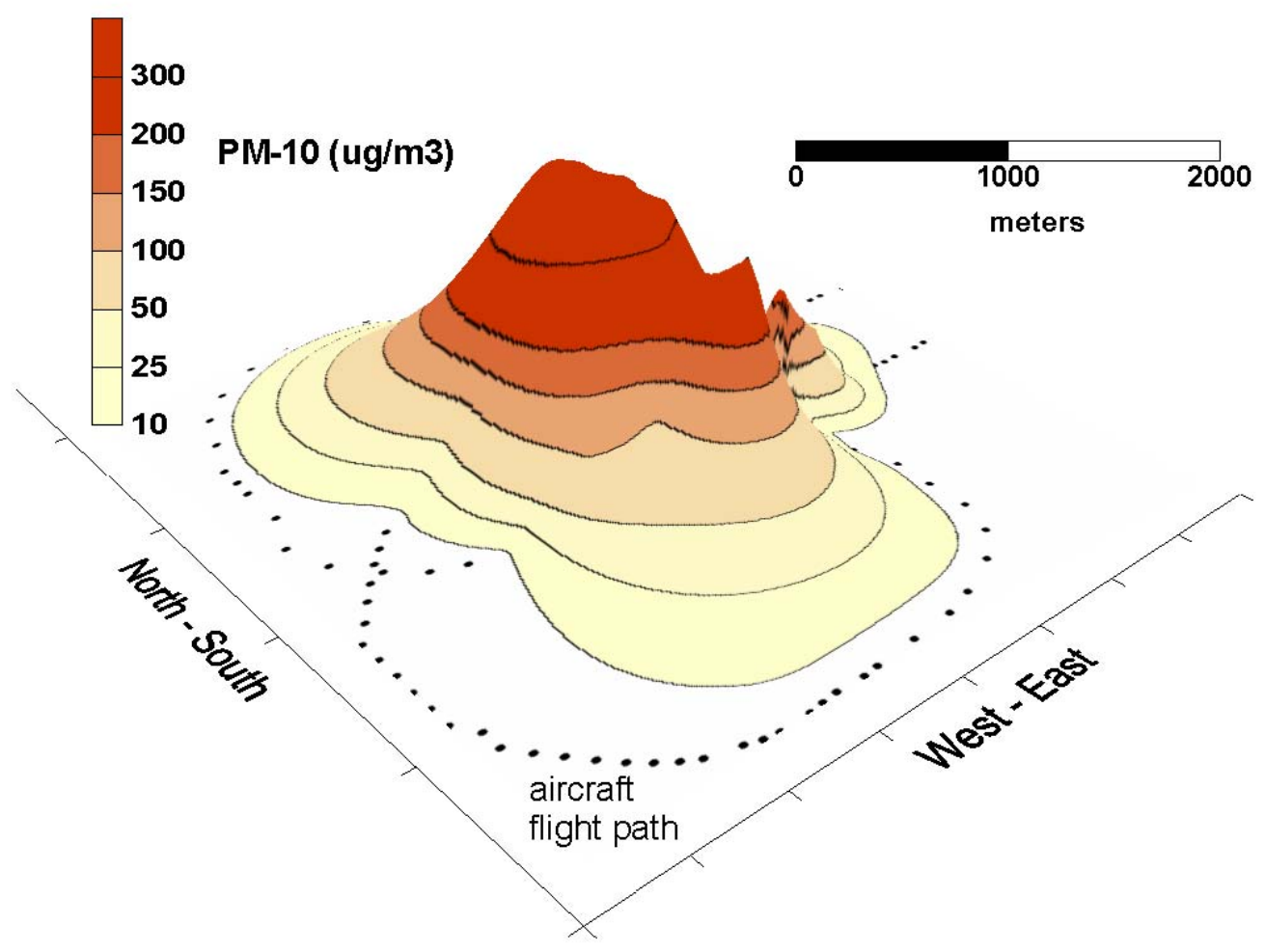

Figure 14. Surfer $8 \AA$ "volume" surface used to integrate lateral cloud concentrations (giving mass per unit cloud height in $\mu \mathrm{g} \mathrm{m}^{-1}$ ).

\section{CONCLUSIONS}

The July 11, 2007 NSTR explosive event $(<20,000 \mathrm{lb}$ TNT-equivalent) produced a mushroom-like dust cloud that rose approximately 2,500-3,000 ft AGL and dissipated quickly (within 5 miles of the source). In general, the size and persistence of this cloud were less than expected (or that might occur in other areas), likely due to the coarse sand and subsurface conditions that characterize the immediate NSTR area. Maximum short time-averaged (1-sec) PM-10 concentrations at the center of the cloud immediately after the event reached $421 \mu \mathrm{g} \mathrm{m}^{-3}$ but were rapidly reduced (by atmospheric dispersion and fallout) to near background levels $\left(\sim 10 \mu \mathrm{g} \mathrm{m}^{-3}\right)$ after about 15 minutes. This occurred well within the INL Site boundary, about $8 \mathrm{~km}$ ( 5 miles $)$ from the NSTR source. These findings demonstrate that maximum concentrations in ambient air beyond the INL Site boundary (closest is $10.9 \mathrm{~km}$ from NSTR) from these types of tests would be well within the $150 \mu \mathrm{g} \mathrm{m}^{-3}$ 24-hour NAAQS for PM-10.

Using the aircraft measurements and geostatistical techniques, the volume $\left(1.64 \mathrm{E}+9 \mathrm{~m}^{3}\right.$ or $\left.1.64 \mathrm{~km}^{3}\right)$ and mass $(250 \mathrm{~kg})$ of the PM-10 dust cloud were successfully quantified, and a PM-10 emission factor (20 $\mathrm{kg} \mathrm{m}^{-3}$ crater soil volume) was developed for this specific type of event at NSTR. The $250 \mathrm{~kg}$ of PM-10 mass estimated from this experiment is almost seven times higher than the $36 \mathrm{~kg}$ estimated for the EA (DOE-ID 2007) using available EPA (1995) emission factors.

Finally, this work demonstrates that the use of advanced aircraft-mounted instruments operated by experienced atmospheric research groups (like the INL/ARC team) can safely and effectively assess difficult air pollutant questions at the INL Site and elsewhere that cannot be otherwise answered. This site-specific, measurement-based assessment provides valuable input to stakeholders in judging the risks 
associated with these types of events and NSTR project staff in the development of future experimental design and environmental impact assessments.

\section{REFERENCES}

Chow, J.C., Watson, J.G., Lowenthal, D.H., Richards, L.W., 2002, Particle light scattering and PM2.5, Environmental Monitoring and Assessment, 79, 29-45.

DOE, 2007, Final Environmental Assessment for the National Security Test Range, DOE/EA-1557, April 2007.

EPA, 1995, "Compilation of Air Pollutant Emission Factors," AP-42, Fifth Edition, Volume 1, Stationary Point and Area Sources, Fifth Edition, U.S. Environmental Protection Agency, January 1995.

Hanna, S.R., Briggs, G.A., Hosker, R.P. Jr., 1982, Handbook on Atmospheric Diffusion, DOE/TIC11223, National Technical Information Service, Springfield, VA.

Radke, L. F., Hobbs, P. V., Eltgroth, M.W., 1980, Scavenging of Aerosol Particles by Precipitation. J. Appl. Meteor., 19, 715-722.

Radke, L. F., Lyons, J.H., Hegg, D.A., Hobbs, P.V., Bailey, I.H., 1984, Airborne Observations of Arctic Aerosols. I: Characteristics of Arctic Haze. Geophys. Res. Lett., 11, 393-396. 